\title{
Co-creative Value for Cultural and Creative Economic Growth - Designing a Cultural Merchandise and Constructing a Marketing Model
}

\author{
Tsen-Yao Chang \\ Department of Creative Design, \\ National Yunlin University of Science and Technology, Yunlin County, Taiwan \\ changty8908@gmail.com
}

\begin{abstract}
With globalization and the advent of technology, consumers are exposed to various cultures through different means; consequently, their selfidentity and recognition of their own culture become confused. Designers can develop merchandise by cultural creativity, converting their cultural creation into the core value of the merchandise which will serve as vehicles for conveying cultural messages and generating cultural identity and regional economic value. But, facing the issue of economic production, the development of contemporary cultural merchandise should, apart from creative design, also consider the demands of daily life, before it can further generate productive value as a business. Owing to the present problems in the process of production of cultural merchandise including the contexts of creativity, productivity of fashion trends, and additional functions, the specific basis for the evaluation of designs are often wanting; as a result, designers' works are not echoed to and recognized by consumers, which leads to difficulties in sales. When designers have a commercial concept when they are designing a cultural merchandise, they involve both the design aspect and the commercial value; in this aspect a business model can be a tool offering choices for the core strategies of the business (Shafer, Smith, and Linder, 2005); it is for profit (Afuah, 2004) that designers set and execute business models. This study makes a reference to Osterwalder and Pigneur's (2010) Business Model Canvas, which is comprised of nine elements. These include value proposition, customer segments, distribution channels, customer relationship, revenue streams, key resources, key activities, key partners and cost structure.

With reference made to the said Business Model Canvas, this study contemplated how to establish models for designing cultural merchandise and marketing them. We thus adopted the approach of using an expert focus discussion and gathered information in two stages. Stage one involves two focus group meetings, to which experts with experience in cultural merchandise-related design, business start-up, and marketing, ten of them in all, were invited. The meetings were conducted using semi-structured interviews, encouraging the participating experts to share their practical experiences. The interview transcripts were coded in the scope of commerce and marketing to construct a hub-and-spoke type model for designing and marketing cultural merchandise. Stage two, launched in Northern, Central and Southern Taiwan, respectively, invited
\end{abstract}


experts in the industry, government and academia from these regions, 18 of them in all, to the meetings on the related issues including marketing cultural merchandise. In the phase of data analysis, the recommendations of the participating experts were integrated, and the Business Model Canvas was further referenced in an attempt to establish a model for designing cultural merchandise and to deduce business and marketing models that are consistent with the design of cultural merchandise.

The findings hereof will propose a thinking model for the business operations and marketing of cultural merchandise, in which the key elements interrelate. The mode is intended to encourage the industry or designers to make reference to it when developing their design and implementing subsequent marketing strategies, so as to integrate all aspects such as cultural creativity, creative design, and business economics, in order to jointly generate economic value for the cultural merchandise in the modern market.

Keywords: Co-Creative Value, Cultural Merchandise Design , Business Model Canvas, Business Start-Up, Cultural Industry Business.

\section{$1 \quad$ Research Context and Motivation}

With globalization and the advent of technology, consumers are exposed to various cultures through different means which thus creates confusion in terms of their selfidentity and recognition of their own culture. Designers can develop merchandise by cultural creativity, converting their cultural creation into the core value of the merchandise which will serve as vehicles for conveying cultural messages and generating cultural identity and regional economic value. Culture has become the critical chance to add value to various fields and to create distinction and uniqueness for marketing, while merchandise provides a media for culture transfer, and an opportunity to create economic value and source of inspiration for designers.

But, facing the issue of economic production, the development of contemporary cultural merchandise should, apart from creative design, also consider the demands of daily life, before it can further generate productive value into a business. Owing to the present problems in the process of cultural merchandise production, such as contexts of creativity, productivity of fashion trends and additional functions, specific basis for evaluation of designs are often wanting; as a result, the designers' works are not echoed to and recognized by consumers, which leads to difficulties in sales. Going back to the consideration of practical marketing and its costs, it often takes a short time for a developed merchandise to appear on the market, easily leading to the gap between abstract concepts and the tangible product; besides, there is a difference between the idea of introducing culture into the merchandise design and designing general merchandise. Therefore, the study hopes to establish a cultural merchandise design dimension model through analyzing the design elements of current cultural merchandise sold in the market and systematically conducting inductive integration, which provides a concept direction for designers, reduces the incorrect use of cultural contexts with the limited development period and increases the feasibility of an 
opportunity for cultural merchandise design and innovation; and, analyzes the business strategies and ways of overall cultural and creative industry, expecting to conclude a set of rules for an innovative business model for the local industries.

\section{Literature Review}

\subsection{Culture Multiple Value}

Lash and Urry (1994) thought there is a reciprocal relationship between culture and economy, and economy can include various commercial behaviors., Culture is manufactured, produced, and presented as different physical merchandise or tourism experience due to economy, while economic activities are added with emotional identification and heterogeneity and recognition brought about by various elements of culture connotation such as stories and emotion. Culture is an indispensable element in our life and spirit. A new design mode should be figured out in this new era to catch up with the trends and be popular among people, using innovative design to find the design balance between globalization and localization of cultural merchandise development. The value of a sustainable culture business should be created and established with innovation as promoted by creative thinking.

In the 21st century, people's lives are much better than that in the previous times. In accordance with psychologist Maslow's Need-Hierarchy Theory proposed in 1953, the spiritual life of security, affiliation, self-esteem as well as self-realization will be pursued after one's physiological needs are achieved. Maslow's theory has been established and spread for a long time; however, in the book Marketing 3.0: From Products to Customers to the Human Spirit, written by Kotler, the father of modern marketing (Kotler, et al., 2010), Zohar's Spiritual Capital: Wealth We Can Live by was cited to reveal that Maslow himself had admitted that the hierarchy theory shall be reversed, namely, self-realization is the basic need. In the past, consumption was thought to be the minimum requirements to maintain life, with thrift, suitability and endurance as principles for public consumption, but there is an increasing pursuit of style as influenced by urbanization, and these styles are no longer considerations depending on function; instead, the single style in a complex modern society cannot satisfy the expectation and requirements of modern consumption any more due to this era shift (Walker, 1990). Some people hold the opinion that there shall be no value judgment on culture, but under the real situation, culture is an important factor whether for commerce or for countries, and it cannot be denied that culture has possessed a strong power and function (Sadashige Aoki, 2010, P37). Thus, the study conceives that cultural merchandise has a characteristic of cultural implication and feasibility of creating value, which are deeply discussed.

\subsection{Culture Value in the Design of Merchandise-Cultural Merchandise Design}

Values, concepts and vocabularies among different countries can be delivered through cultural merchandise, while excessive dependence on imports can lead to gradual disappearance of the local original culture (Jesse, 2010). The reason for culture 
generating value lies in the fact that its emotion and story connotation can resonate with the consumers, which conforms to current consumers' purchasing habits and preferences. Danish futurist Dr. Rolf Jensen proposed that consumers seek for a story and emotional experience linkage with the merchandise through purchasing behavior (Jensen, 1999). Chen (2004) pointed out that if the merchandise can render its value through cultural activities, the meaning of the cultural merchandise can thereby be formed. Cultural merchandise plays as the vehicle of deeper emotional communication between the local culture and consumers which can guide the public to further understand the profound connotation of culture and grasp the contained emotional value.

Consumers often consider the invisible psychological satisfaction in addition to the consideration of function and application when purchasing merchandise (Verganti, 2009). Consumers have lost interest in merchandise of mass production (Delaney et al., 2002, P46) and designers intend to convert merchandise into vehicles for culture transfer through design means, which satisfies consumers with emotional, aesthetic and social demands in addition to its functions of use (Moalosi et al., 2007). Thus, the design of cultural merchandise not only focuses on the merchandise itself, but also on the presentation of local culture connotation; the function of local cultural merchandise is not limited to the function of use, but may contain stories, history, local experience, local features and other things behind the place (Chen, 2005). Cultural merchandise can tell the story of a local culture and increase the value of the consumer's connection with the merchandise (Li, 2004). Hence, in terms of the delivery of cultural merchandise, the story and emotion possessed by culture must be followed, and the cultural quality should be adopted to strike a chord to consumers; thus marketing acceptance of cultural merchandise can be increased through design.

\subsection{Cultural Industry Business and Development}

Among the industry development in various regions, there are many traditional industries which have lasted for many generations and have witnessed the rise and fall of the Taiwan economy. In this era of digital and scientific technology development, how can the traditional industries transform in accordance with the modern consumers' lifestyle and add new marketing appeal? Local cultural industries have profound industrial history and most of them uphold the tradition of producing products with superior quality. With the shift of eras, they are faced with the above consumers' lifestyle transformation, policy, resources and other issues in a large environment; those who cannot conform to the trends will gradually be replaced. These local industries contain a cultural context, and their products represent local advantages; in a time of reconsidering cultural value and experience economy, these traditional local industries implicate infinite opportunities for and feasibilities of recreating economic value.

The creative business model of the local industry shall find out the emotional linkage of industries and places to add design creativity and turn emotion into marketing brand by stories with irreplaceable local flavor, which are creative and have a unique industry charm, which is also an important strategy to reshape the sustainable 
business of local value. Along with the development of the cultural and creative industry, cultural source can be preserved and infused into consumer's daily life in a timely manner through commercialization and the introduction of digital technology. Local cultural feature is turned into economy through brand creativity, and converts the connotation of local culture into productive value. Creativity is self-identification after being touched, while brand is the vehicle, means or method to realize cultural design creativity. Thus, to put it in a simple way, local brand creativity is to achieve a design taste or lifestyle of local culture through creativity design and brand marketing (Lin, 2005). Local culture has colorful connotations and dimensions, which turns local scenery, folk arts and techniques, traditional industries and history into merchandise with local cultural elements included, bringing culture closer to daily life.

\section{Research Method and Phases}

The study adopted the approach of qualitative research and expert focus discussion and gathered information in two major phases. Stage one involves two focus group meetings, to which experts with practical experiences in cultural and creative merchandise-related design, business start-up, and marketing, ten of them in all, were invited. The meetings were conducted using semi-structured interviews, leading the participating experts to share their practical experiences. The interview transcripts were coded in the scope of commerce and marketing to construct a hub-and-spoke type model for designing and marketing cultural merchandise. Stage two, launched in Northern, Central and Southern Taiwan, respectively, invited experts in the industry, government and academia from these regions, 18 of them in all, to the meetings on the issues including marketing cultural merchandise. In the phase of data analysis, the recommendations of the participating experts were integrated, and the Business Model Canvas was further referenced in an attempt to establish a model for designing cultural merchandise and to deduce business and marketing models that are consistent with the design of cultural merchandise.

\subsection{Expert Focus Group in Stage One}

Stage one involves two focus group meetings, to which experts with practical experiences of more than ten years in cultural and creative industry-related fields were invited. The study aims to analyze the design of cultural merchandise. To obtain analysis data of cultural merchandise design, five experts and four experts with practical experiences in cultural and creative industry-related fields were invited, respectively. The first meeting included experts majoring in design and marketing; entrepreneurs in the cultural and creative industry and four experts with practical experiences in design and managing design companies were invited to jointly participate in the second meeting. Through the two meetings, opinions on cultural merchandise design and management were raised by experts with different seniority levels and experiences in the creative and cultural industry, to obtain first-hand information for subsequent qualitative research and analysis. The research copied the contents of the transcripts 
after the expert focus discussion; by use of the coding method of grounded theory, the main category and sub-categories were clarified to set out and construct a marketing model for cultural merchandise design.

\subsection{Expert Focus Group in Stage Two}

The expert focus discussion in stage two, launched in Northern, Central and Southern Taiwan, respectively, was intended to deeply understand the feasibility, development and application of Taiwanese local cultural and creative industry. Experts invited were not limited to the industry, but included experts from the academia and the government to discuss the management and development of the local cultural and creative industry.

Six experts each from the industry, academia and government were invited in the focus group of the three sections, respectively, with a total of 18. Two experts from the academia and four experts from the industry were invited to Northern Taiwan; one expert from the government and five experts from the industry were invited to Central Taiwan; one expert each from the academia and from the government and four experts from the industry were invited to Southern Taiwan. Opinions on the cultural and creative industry development status were presented based on their practical experience, which were used for subsequent research and analysis.

\section{$4 \quad$ Research Results and Discussion}

The study conceives that marketing and commerce should be considered when designing cultural merchandise, which involves deliberating the subsequent merchandise development opportunities and feasibility, and using the gained profit to extend the life span of the merchandise and creating more productive value and business opportunity. The two-stage study extends from cultural merchandise design and marketing to the business opportunity of the cultural and creative industry, providing designers or those who are interested in running the cultural and creative industry with a guide.

The study in stage one proposed a hub-and-spoke type of thinking model for designing and marketing cultural merchandise (as Figure 1) after coding based on the contents of experts' focus meetings, within which any element can be taken to determine the features of the cultural merchandise that are intended to be developed, and through which whether the existing products possess these marketing elements can be inspected. Taking coming into the market as an example, it is divided into seven major programs, which have to be checked one by one to make sure that they meet the essential requirements before going to the market. This means they have to consider whether technical barriers should be set up, whether capital collection is sufficient, what the size of the economic scale is, whether creative thinking has been included in the merchandise, whether the human aspect of the cultural merchandise should be applied, what the market position is and when the best opportunity for entering the market is, all of which have to be tackled one by one. Whether there is deficiency in 
the launching plan of the merchandise shall be discovered and enhanced during the course of implementing it; whether there are other aspects for further analysis should also be considered. A referable recyclable design concept for cultural merchandise should be established from the design phase to the product's launch.

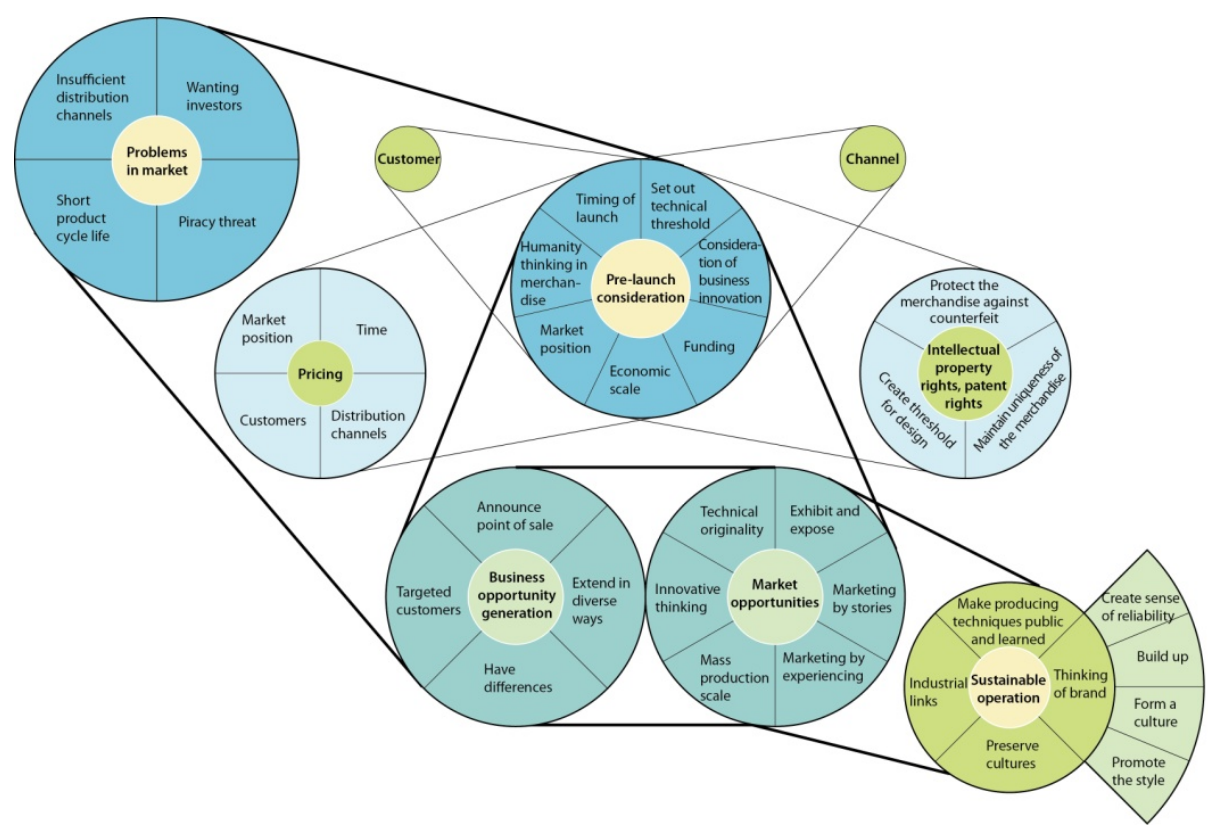

Fig. 1. A cultural merchandise and constructing marketing model

Through this model, the initial stage of design can be shortened with the integrated design thinking way, which makes the concept of cultural merchandise design become more thorough; each element can be considered independently or correlatively, and the influences and choices of other design and marketing should also be taken into consideration when starts from a certain hub-and-spoke in the model, through which the design and development period can be shortened and designers can find new creating opportunities. Personal experiences and ideas can bring different styles to the cultural merchandise and create value through the design.

The study summarizes that the marketing aspect cannot be ignored if creative value of the cultural merchandise shall be achieved. Cultural merchandise has to create commercial value instead of works of arts laid on the shelf. Thus, through grounded theory to code and construct the design strategy and marketing strategy of cultural merchandise, designers are allowed to analyze the commercial aspect of the design and not just consider their work from the perspective of their own profession fields. The cultural merchandise design thinking model has a hub-and-spoke structure, which presents the correlation of different strategies. Designers should think in an integrated way when designing a cultural merchandise so as to construct all design key points of the cultural merchandise completely, and they must think from the angle of brand 
creation in order to further expand the value of the cultural merchandise,. Thus, through the second stage of the study and by the experience sharing of the experts from the industry, academia and government, the thinking context of cultural merchandise has been extended with brand management as the main axis. With this, the sustainable business cycle of the creative and cultural industry was proposed (Fig. 2).

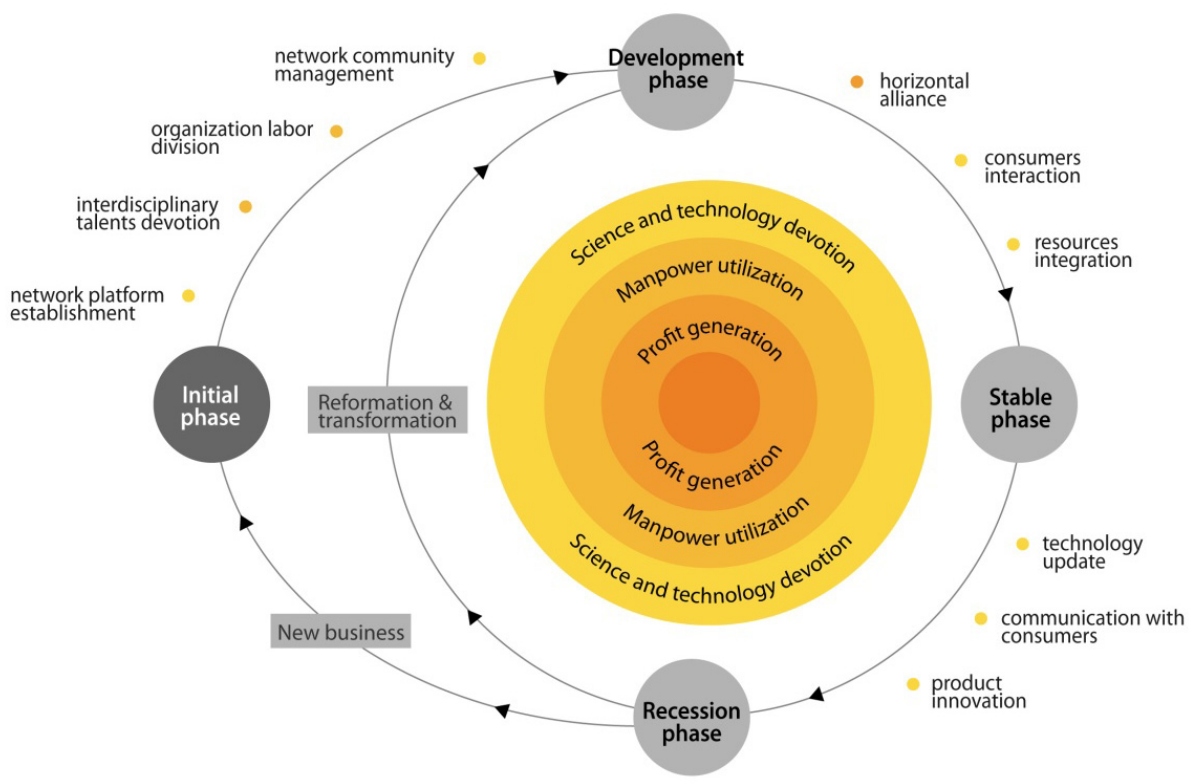

Fig. 2. The sustainable business cycle of the creative and cultural industry

The study proposed three main issues, which include interdisciplinary talents integration, emotional stories and digital technology appreciation, to cut into the business development opportunity of the local cultural and creative industry that are consistent with the coding of the focus discussion. Using emotional connotation as the core, locally featured stories should be dug out to present the product's uniqueness and identity in the global market; as for the combination process of local culture with digital technology, interdisciplinary talents should be introduced to act as bridges for communication to lower time and manpower cost; on the application of digital technology, its aid to the industry shall be understood. Good use of digital technology can reduce business cost and accelerate the advertisement effect of brands; however, what the features and core are shall be clarified first before employing scientific technology to create optimal usage and develop a business model suitable for local cultural and creative industry operation.

Enterprises should keep moving forward even with continued business and must keep itself up to date with the market to achieve the goal of creating a sustainable business by developing and innovating products that are consistent with consumers' preference. The practical aspect of sustainable development is generating profit, with 
which the business can expand and attract more talents, thereby creating job opportunities. Thus, it is essential whether for operators, designers or interdisciplinary talents acting as a bridge that they shall have commercial concept to construct a business model suitable for brand operation, through which business core strategy and communicative strategy can be selected to obtain profits. .Looking at it from a business cycle, from the initial phase, development phase to its steady phase, the core value shall remain the center of operational strategy in the different phases to maintain the consistency of the enterprise's brand management, and to conduct strategy planning for manpower utilization and scientific technology application. In the business guidelines of the different phases, the demands of various talents and scientific technology are different due to the difference in brand stability. In the initial stage, a future development strategy can be planned according to the overall operation and then the guidelines can be adjusted along with the changes in actual operation status and marketing environment, which allows the enterprises to make use of experience accumulated in the past to develop a new business, or to create a sustainable business cycle by transforming its own capitals when it enters into the recession phase. However, the types and elements of the cultural and creative industry are various. The study proposes an overall thinking direction for the cultural and creative industry business model to provide references for entrepreneurs in such field. In this modern era, they shall ponder over how to use digital technology as a tool, how to adhere to the original purpose of entrepreneurship and how to develop an exclusive sustainable business cycle directed at the creative features of its own brands.

Acknowledgments. The authors gratefully acknowledge the financial support for this research provided by the National Science Council of Taiwan under Grant No. NSC 102-2420-H-224 -004.

\section{References}

1. Afuah, A.: Business models a strategic management approach. McGraw-Hill/Irwin, New York (2004)

2. Chen, C.L.: Analyze the Cultural Production and Media Role of the Economic MarketFour Cases as an Example. Shih Hsin University, Taipei (2004)

3. Chen, P.C.: Study On the Cooperative \& creative design works for local culture commodities-with a case study of Caotun straw goods straw goods, Yunlin. Unpublished master's thesis, National Yunlin University of Science and Technology (2005)

4. Delaney, M., McFarland, J., Yoon, G.H., Hardy, T.: Global Localization, Innovation Global Design and Cultural Identity, Summer, pp. 46-49 (2002)

5. Jensen, R.: The dream society: The coming shift from information to imagination. McGraw-Hill, London (1999)

6. Chu-Shore, J.: Homogenization and Specialization Effect of International Trade: Are Cultural Goods Exceptional? World Development 38, 37-47 (2010)

7. Kotler, H.K., Setiawan, I.: Marketing 3.0:From Products to Customers to the Human Spirit. Wiley (2010)

8. Lash, S., Urry, J.: Economies of Signs and Space. Sage, London (1994) 
9. Li, Y.F.: The Application to The Symbol of Cultural Commodity -With a Case Study of Cultural Creative Industry in Hu-ban village. Unpublished master's thesis, National Yunlin University of Science and Technology, Yunlin (2004)

10. Lin, R.T.: Cultural creativity added design value. Art Appreciation 1(7), 26-32 (2005)

11. Moalosi, R., Popovic, V., Hickling-Hudson, A.: Product analysis based on Botswana's postcolonial socio-cultural perspective. International Journal of Design 1(2), 35-43 (2007)

12. Osterwalder, A., Pigneur, Y.: Business Model Generation, 1st edn. John Wiley \& Sons, Inc., Hoboken (2010) (published simultaneously in Canada)

13. Aoki, S.: Method of Cultural Marketing: The Power of Culture. CommonWealth, Taipei (2010)

14. Shafer, S.M., Smith, H.J., Linder, J.C.: The power of business models. Business Horizons 48(3), 199-207 (2005)

15. Verganti, R.: Design-driven innovation: Changing the rules of competition by radically innovating what things mean. Harvard Business, Boston (2009)

16. Walker, W.A.: Craft and design, design history and the history of design. Pluto, London (1990) 